\title{
Temporal Trends in Hospitality and Mortality Due to Colorectal Cancer in Santa Catarina from 2000 to 2017
}

\section{Esthefânia de Souza Maciel ${ }^{1 *}$, Giovanna Grunewald Vietta ${ }^{2}$, Mariano Kolankiewicz Filho ${ }^{3}$, Camila Fabris ${ }^{1}$, Ana Luisa Pedrazza ${ }^{4}$, Adriel Vernes Abu El Haje ${ }^{1}$ and Márcia Regina Kretzer ${ }^{5}$}

${ }^{1}$ Medical Doctor, Universidade do Sul de Santa Catarina - UNISUL, Brazil

${ }^{2} \mathrm{PhD}$ in Medical Sciences, Professor of Medicine, Universidade do Sul de Santa Catarina - UNISUL, Brazil

${ }^{3}$ General and Laparoscopic Surgeon, Member of the Brazilian Society of Digestive Endoscopy, Hospital Vale do Araguaia, Brazil

${ }^{4}$ Medical Student, Universidade do Sul de Santa Catarina - UNISUL, Brazil ${ }^{5}$ PhD in Public Health, Professor of Medicine, Universidade do Sul de Santa Catarina - UNISUL, Brazil

*Corresponding Author: Esthefânia de Souza Maciel, Medical Doctor, Universidade do Sul de Santa Catarina - UNISUL, Brazil.
Received: November 08, 2021

Published: November 23, 2021

(C) All rights are reserved by Esthefânia de Souza Maciel., et al.

\section{Abstract}

Background: Colorectal cancer (CRC) is among the five most frequent cancers in Brazil, and Santa Catarina is one of the most affected states. Mortality due to CCR is high. This type of cancer has a poorly explored hospitalization profile in the literature.

Objective: To analyze the temporal trend of hospitalization and mortality due to CRC in Santa Catarina between 2000 and 2017.

Methods: Ecological study of time series with data from the Hospital Information System and Mortality Information System available in DATASUS. Simple linear regression, confidence interval 95\%, $\mathrm{p}<0.05$.

Results: There were 37,513 hospitalizations and 7,809 deaths in the analyzed period. The hospitalization rates showed a tendency to increase in the state, from $15.72 / 100,000$ in 2000 to $87.53 / 100,000$ in 2017, and in both sexes. The male sex presented the highest hospitalization rates, from $15.63 / 100,000$ at the beginning to $90.35 / 100,000$ at the end $(\mathrm{p}<0.001)$. Tendency to increase in the age groups from 30 years in both sexes. The mortality trend presented an increase from 7.92/100,000 deaths in 2000 to 12.86/100,000 in 2017. The same trend was observed in both sexes, female age groups between 40-49 and male age groups between 40-69. Tendency to reduction in the 20-29 age group in females $(\mathrm{p}=0.017)$.

Conclusion: Santa Catarina has a tendency to increase hospitalization and mortality rates in both genders and in young adults. Male sex has the highest rates of hospitalization and death.

Keywords: Colorectal Cancer; Mortality; Hospitalization; Trend

\author{
Abbreviation \\ CRC: Colorectal Cancer
}

\section{Introduction}

Colorectal cancer (CRC) is among the five most common types

Citation: Esthefânia de Souza Maciel., et al. "Temporal Trends in Hospitality and Mortality Due to Colorectal Cancer in Santa Catarina from 2000 to 2017". Acta Scientific Gastrointestinal Disorders 4.12 (2021): 34-41. 
of cancer, comprising tumors originating in the colon, rectum, and anus, which mostly start from intestinal polyps [1].

CRC is in third place in the global incidence ranking, being responsible for more than 1.8 million new cases in 2018 - approximately $80 \%$ of these occur in the population over 55 years. The incidence rate according to gender is 9.5 cases per 100,000 men and 10.2 cases per 100,000 women. In Brazil, the incidence rate of CRC also occupies the third place, following breast and prostate cancer [2]. It is noteworthy that the incidence rate of Brazilians is high, 16.83 and 17.90 new cases per 100 thousand men and women, respectively [3].

The trend of incidence of CRC around the world varies widely, being essentially associated with differences in the Human Development Index (HDI). Three main trend patterns were identified and classified according to the highest HDI to the lowest, respectively: the first, with a decrease in incidence and mortality rates; the second, with an increase in incidence and a decrease in mortality; and, the third, with an increase in both rates. Brazil is in this third pattern, which is typical of developing countries [4]. In the state of Santa Catarina, the incidence is also increasing. In 2008 , the incidence rate of CRC was 14.02/100,000 in men and $16.37 / 100,000$ in women [5]. Ten years later, the incidence rate rose to $16.62 / 100,000$ in men and $17.28 / 100,000$ in women [3].

There are few studies related to CRC hospitalization. In the United States, the number of hospitalizations due to CRC has been increasing recently, especially in the age groups below 65 years and decreasing above that age [6].

Mortality due to CRC in the world ranks second among cancers, comprising $9.2 \%$ of deaths. In the distribution by genders, it causes $9.0 \%$ of cancer deaths in men and 9.5\% in women. In Brazil, CRC is responsible for approximately $11 \%$ of cancer deaths [2] (7.6\% in males and $9.0 \%$ in females) [1]. There is a time trend of increasing mortality in the country of $7.3 \%$ in men and $6.5 \%$ in women per year between 1996 and 2015 [7] in all Brazilian regions, with the Southern region presenting the highest mortality [8].

Currently, there is an increase in the incidence of CRC in Brazil related to modifiable risk factors - mainly in more developed regions - including habits related to food and lifestyle (e.g., the consumption of processed meats; consumption of more than $500 \mathrm{~g} /$ week of red meat; intake above $30 \mathrm{~g}$ of ethanol/day and smoking) $[1,9]$.

CRC represents a major global and national public health problem due to its high social and economic cost. The epidemiological profile of hospitalization and mortality regarding this condition is still little explored in the literature, especially in Santa Catarina, therefore being the rationale of this investigation. The results may contribute to increase knowledge in the area and support the implementation of new health practices, especially in primary health care and specialized services. Thus, we aim is to analyze the temporal trend of hospitalization and mortality due to colorectal cancer (CRC) in Santa Catarina between 2000 and 2017.

\section{Materials and Methods}

This is an ecological study of temporal trends carried out in the state of Santa Catarina, which has a population of 7,075,494 people and an HDI of 0.774, according to the Brazilian Institute of Geography and Statistics (BIGS) ${ }^{(10)}$. Data related to mortality and hospitalization due to colorectal cancer were obtained from the Mortality Information System (MIS) and the Hospital Information System (HIS) respectively, available as public domain on the Department of Informatics (DATASUS) - Ministry of Health website (HIS: http:// tabnet.datasus.gov.br/cgi/deftohtm.exe?sih/cnv/nrsc.def; MIS: http://tabnet.datasus.gov.br/cgi/deftohtm.exe?sim/cnv/obt10pr. def), with a copy in Comma Separated Values (CSV) format.

The study population consisted of all hospitalized subjects and those who died due to CRC in the state of Santa Catarina from 2000 to 2017 , aged 20 years or older and notified with cancer according to ICD-10, C18 (colon), C19 (rectosigmoid junction), C20 (rectum) and C21 (anal canal).

The calculation of general and specific rates was performed using BIGS data regarding the number of inhabitants of the state according to the 2000 and 2010 census, as well as inter-census estimates. The dependent variables included the general rate of hospitalization and mortality due to CRC in the state of Santa Catarina and the specific rates according to gender and age group by gender calculated per 100,000 inhabitants. The independent variable was the year in which the information was collected.

The standardized hospitalization and mortality coefficients and the simple linear regression method were used to analyze 
the temporal trends in mortality due to the CRC. The standardized hospitalization and mortality coefficients were considered as a dependent variable, and the years of the study calendar as an independent variable, thus obtaining the model estimated as follows: $y$ $=\mathrm{b} 0+\mathrm{b} 1 \mathrm{X}$, where $\mathrm{y}=$ standardized coefficient, $\mathrm{b} 0=$ average coefficient of the period, $\mathrm{b} 1$ = average annual increase and $\mathrm{X}=$ year. The standardization of hospitalization and mortality coefficients due to CRC was performed using the direct method, considering the population of the State of Santa Catarina from 2000 to 2017 as the standard population.

According to Resolution 510, approved by the National Health Council on April 7, 2016, the use of information for research purposes from databases whose information is aggregated, without the possibility of individual identification and public access, does not require submission to and ethical review by a committee.

\section{Results and Discussion}

A total of 37,513 hospitalizations and 7,809 deaths due to CRC was registered in the State of Santa Catarina between the years
2000 and 2017.

The general hospitalization rates showed a tendency to increase in the analyzed period, with an increase of 4.57 cases per year, from $15.72 / 100,000$ in 2000 to $87.53 / 100,000$ in 2017 (Figure 1). The same profile was observed in both genders, with men having the highest hospitalization rates, from $15.63 / 100,000$ at the beginning to $90.35 / 100,00017$ years later. The female gender presented a variation in the rates from $15.82 / 100,000$ to $84.72 / 100,000$ in 2017 ( $\mathrm{p}<0.001)$ (Figure 2).

In relation to age groups, an increasing trend was observed in females following 30 years of age. Larger increments were identified between 60-69 and 70-79 years. In the latter, there was an increase of 12.93 cases per year, with a variation of $65.56 / 100,000$ at the beginning of the analyzed period and 283.35/100,000 at the end. The male age groups from 30 years onwards also showed increases, especially those from 60-69 and 70-79 years old, with an emphasis on the 70-79 years old, with a rate from 89.49 in 2000 to 373.53 in $2017(\beta=20.71)$ (Table 1).

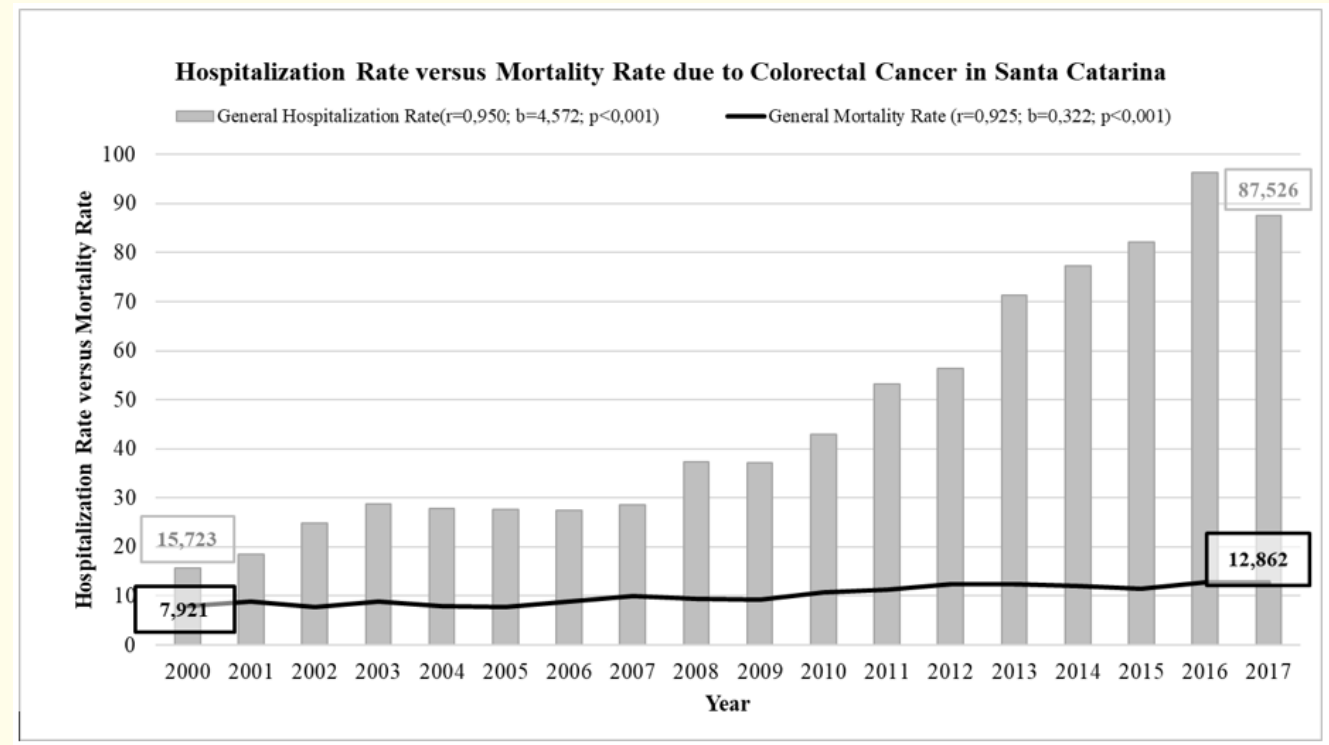

Figure 1: Trend in hospitalization and mortality rates due to colorectal cancer in Santa Catarina, from 2000 to 2017. 


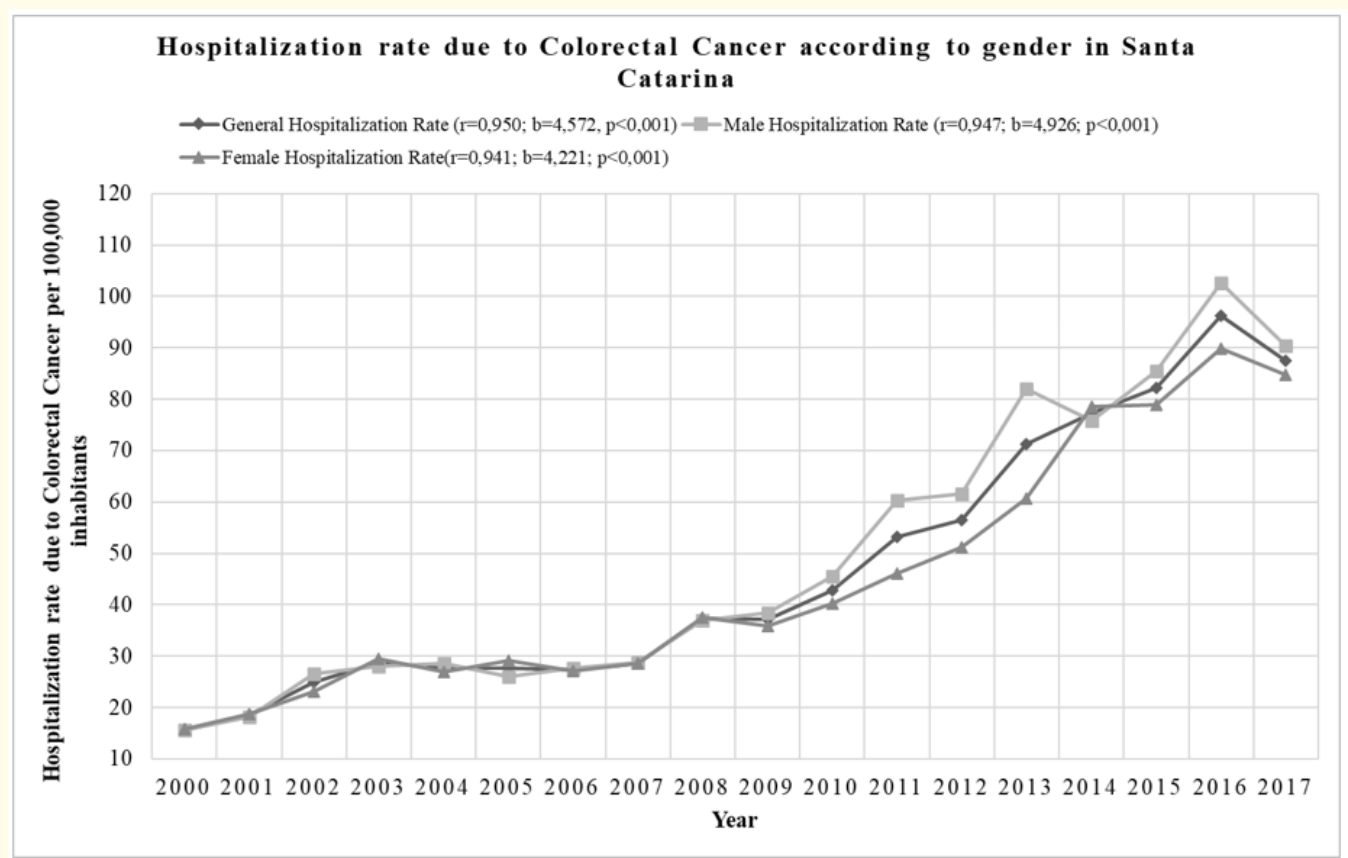

Figure 2: Trend in hospitalization rates due to colorectal cancer according to gender in Santa Catarina, from 2000 to 2017.

\begin{tabular}{|c|c|c|c|c|c|c|}
\hline \multicolumn{7}{|c|}{ Hospitalization rate } \\
\hline Variable & General rate & $\mathbf{R}$ & Beta coefficient & Confidence interval & P value & Status \\
\hline \multicolumn{7}{|c|}{ Male age group } \\
\hline $20-29$ & 9.993 & 0.263 & -0.211 & $-0.622 ; 0.199$ & 0.291 & Not changed \\
\hline $30-39$ & 15.989 & 0.712 & 0.701 & $0.335 ; 1.607$ & 0.001 & Increased \\
\hline $40-49$ & 34.195 & 0.923 & 3.056 & $2.382 ; 3.731$ & $<0.001$ & Increased \\
\hline $50-59$ & 74.132 & 0.946 & 8.113 & $6.645 ; 9.581$ & $<0.001$ & Increased \\
\hline $60-69$ & 150.297 & 0.927 & 16.261 & $12.774 ; 19.748$ & $<0.001$ & Increased \\
\hline $70-79$ & 211.902 & 0.925 & 20.706 & $16.204 ; 25.208$ & $<0.001$ & Increased \\
\hline $80+$ & 156.942 & 0.811 & 12.170 & $7.510 ; 16.830$ & $<0.001$ & Increased \\
\hline \multicolumn{7}{|c|}{ Female age group } \\
\hline $20-29$ & 7.558 & 0.085 & -0.047 & $-0.341 ; 0.246$ & 0.736 & Not changed \\
\hline $30-39$ & 16.441 & 0.863 & 0.935 & $0.645 ; 1.225$ & $<0.001$ & Increased \\
\hline $40-49$ & 39.415 & 0.919 & 3.804 & $2.942 ; 4.666$ & $<0.001$ & Increased \\
\hline $50-59$ & 68.822 & 0.925 & 6.593 & $5.155 ; 8.073$ & $<0.001$ & Increased \\
\hline $60-69$ & 106.408 & 0.893 & 10.239 & $7.507 ; 12.971$ & $<0.001$ & Increased \\
\hline $70-79$ & 148.045 & 0.883 & 12.933 & $9.294 ; 16.573$ & $<0.001$ & Increased \\
\hline $80+$ & 119.420 & 0.879 & 6.268 & $4.463 ; 8.073$ & $<0.001$ & Increased \\
\hline
\end{tabular}

Table 1: Hospitalization rate related to colorectal cancer in Santa Catarina according to gender and age groups, from 2000 to 2017. 
The mortality trend due to CRC in Santa Catarina increased the rate by 0.32 per year $(\mathrm{p}<0.001)$, varying from $7.92 / 100,000$ deaths in 2000 to $12.86 / 100,000$ in 2017 (Figure 1). The same trend is observed in genders with similar rates, with the male gender showing a greater increase, 0.40 per year (Figure 3).
In relation to age groups, a reduction in the mortality rate $(\beta=-0.02)$ between 20 and 29 years was identified in females. In the 40-49 age group, there was a tendency to increase from $3.54 / 100,000$ deaths related to CRC at the beginning of the period to $6.54 / 100,000$ at the end (Table 2).

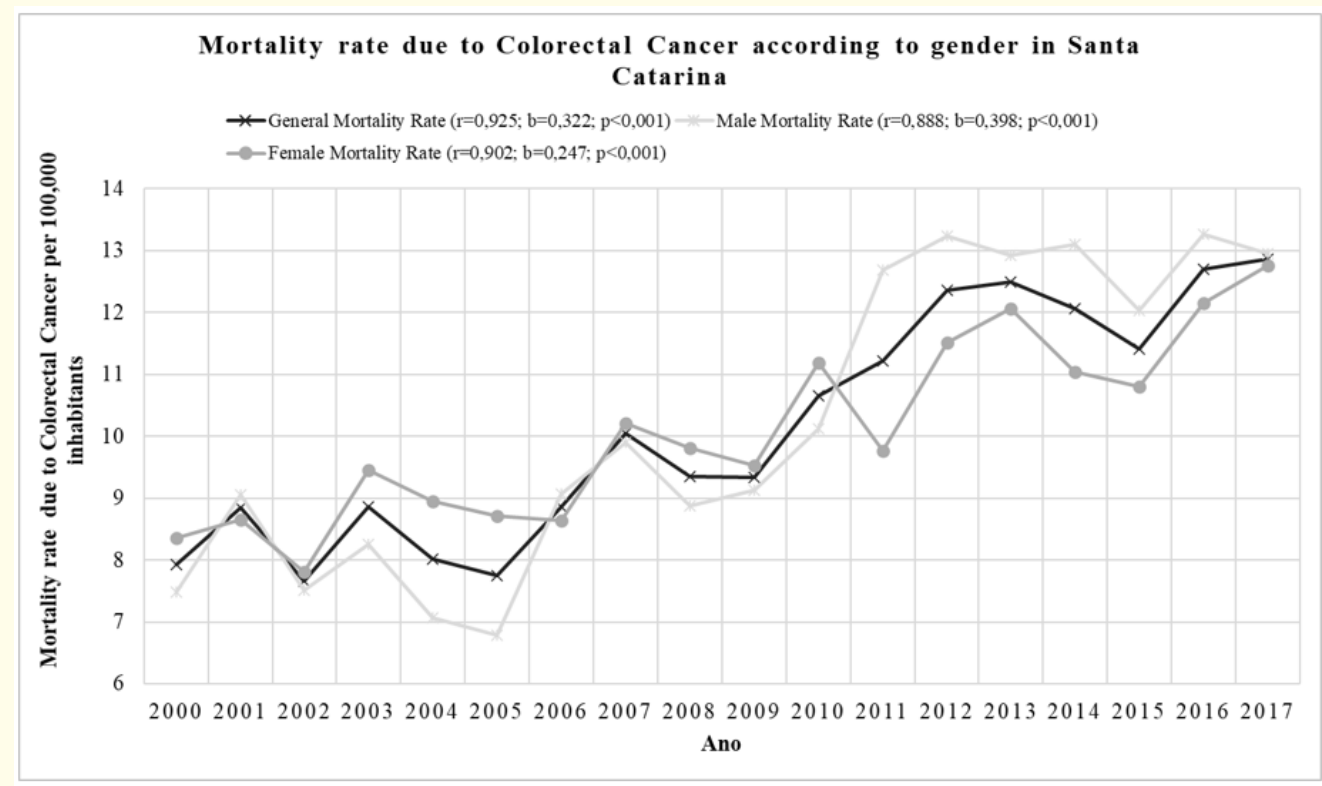

Figure 3: Trend in mortality rates due to colorectal cancer in Santa Catarina according to gender, from 2000 to 2017.

\begin{tabular}{|c|c|c|c|c|c|c|}
\hline Variable & General rate & $\mathbf{R}$ & Beta coefficient & Confidence interval & $P$ value & Status \\
\hline \multicolumn{7}{|c|}{ Male age group } \\
\hline $20-29$ & 0.411 & 0.257 & -0.014 & $-0.042 ; 0.0144$ & 0.303 & Not changed \\
\hline $30-39$ & 1.456 & 0.011 & 0.001 & $-0.043 ; 0.045$ & 0.965 & Not changed \\
\hline $40-49$ & 4.724 & 0.551 & 0.140 & $0.028 ; 0.252$ & 0.018 & Increased \\
\hline $50-59$ & 12.36 & 0.708 & 0.394 & $0.186 ; 0.601$ & 0.001 & Increased \\
\hline $60-69$ & 31.235 & 0.707 & 0.850 & $0.400 ; 1.301$ & 0.001 & Increased \\
\hline $70-79$ & 71.006 & 0.450 & 0.941 & $-0.050 ; 1.932$ & 0.061 & Not changed \\
\hline $80+$ & 120.118 & 0.248 & 1.561 & $-1.665 ; 4.786$ & 0.320 & Not changed \\
\hline \multicolumn{7}{|c|}{ Female age group } \\
\hline $20-29$ & 0.330 & 0.556 & -0.023 & $-0.040 ;-0.005$ & 0.017 & Decreased \\
\hline $30-39$ & 1.564 & 0.250 & -0.021 & $-0.063 ; 0.022$ & 0.317 & Not changed \\
\hline $40-49$ & 4.993 & 0.694 & 0.163 & $0.074 ; 0.253$ & 0.001 & Increased \\
\hline $50-59$ & 11.717 & 0.192 & 0.055 & $-0.093 ; 0.203$ & 0.444 & Not changed \\
\hline $60-69$ & 22.616 & 0.022 & 0.017 & $0.406 ; 0.441$ & 0.932 & Not changed \\
\hline $70-79$ & 52.248 & 0.428 & 0.467 & $-0.056 ; 0.990$ & 0.076 & Not changed \\
\hline $80+$ & 104.769 & 0.053 & 0.169 & $-1.506 ; 1.844$ & 0.833 & Not changed \\
\hline
\end{tabular}

Table 2: Mortality rate related to colorectal cancer in Santa Catarina according to gender and age groups, from 2000 to 2017. 
There was a trend towards an increase in males in the 40-49, 50-59 and 60-69 age groups, with higher rates in the latter, with $28.53 / 100,000$ deaths by CRC in 2000 to $38.58 / 100,000$ in 2017 $(\beta=0.85)$ (Table 2).

When analyzing the general trend of hospitalization due to CRC in Santa Catarina, there was a considerable increase in rates between 2000 and 2017. Similarly, data from the Global Cancer Observatory (GLOBOCAN) show an increase in the number of new cases of CRC, with 1,234,000 new cases registered in 2008 and a total of 1,849,518 in 2018 [11,12]. Recent international studies also demonstrate an increase in both CRC-related incidence and hospitalization rates in countries in economic transition, such as Brazil $[4,12]$. However, a Spanish study conducted by Darba., et al. showed a reduction in the number of hospital admissions due to the CRC [13]. The divergences found between these studies can be explained by the different stages of economic development in which the countries mentioned above are. In this sense, a study carried out in 2017 by Arnold and colleagues shows that the countries with a lower HDI present higher incidence and mortality rates due to CRC [4].

In the present study, there was a tendency to increase hospitalization in both genders, with greater increases related to men. Interestingly, in the United States the average hospitalization rate between 2006-2010 was 83/100,000, with higher rates among women [14]. A retrospective analysis carried out in China showed a tendency to increase hospitalizations due to CRC in both genders, but with a female predominance [15], as a recent Brazilian study [16]. According to the National Cancer Institute, the same increase pattern occurred in CRC incidence rates in Brazil over 10 years, from 13/100,000 in men and 15/100,000 in women in 2008 [5] to $16.83 / 100,000$ in men and 17.90/100,000 in women in 2018 [3]. In the state of Santa Catarina, the incidence also increased in both genders in the same period $[3,5]$.

Regarding the age groups, the data obtained in the present study demonstrate similar values in hospitalization rates in all age groups from 30 years old, for both genders, with greater increases in rates between 60-69 and 60-79 years. This conclusion contrasts with the results obtained in an American study that showed a significant decrease in the number of hospitalizations due to CRC, but with a greater proportion of patients under 40, 40-49 and 50-65 years [6]. In contrast, patients from a European country with HDI close to the Brazilian standard also demonstrated an increase in hospitalization rates and incidence due to CRC in both genders and age groups [17]. The increase in the hospitalization trend in both genders and age groups of individuals over 30 years old may be associated to risk factors related to food and lifestyle (e.g., the consumption of red meat, alcohol, and tobacco) which are present in developed regions $[1,9]$.

Here we showed a tendency to increase the mortality rate during the analyzed period in the state of Santa Catarina. GLOBOCAN data show an increase in CRC mortality worldwide, accounting for $8 \%$ of cancer deaths in 2008 and 9.2\% in 2018 [11,12]. The increase in mortality is mainly described in Eastern European countries, Latin America and Asia [4]. Recently, studies carried out in Brazil also show increased time trends in the general mortality rates due to CRC, with higher numbers observed in South and Southeast regions $[7,8]$. In a previous period, Santa Catarina, had already shown a time trend of increased mortality related to CRC [18].

In the current study, the trend of increasing mortality rates was also observed in both genders, which presented similar values although with a greater increase in males. Arnold., et al. analyzed the trends in colorectal cancer in several countries and identified the greatest increase in new cases in males from Brazil [4]. Another study carried out in a Brazilian Southern state, likewise demonstrated an increasing trend in mortality rates for both genders, with higher rates in the male population [19], corroborating the results found here. According to Oliveira., et al. Santa Catarina was the only state to demonstrate - only among men - a mortality rate due to CRC higher than that of South America [9], even though studies in Europe and the United States have shown a reduction in this demographic index $[20,21]$.

Knowing that CRC is one of the cancers most positively associated with socio-economic development, the increase in mortality in Brazilian South and Southeast regions are consistent with this information and may be related to risk factors typical of developed regions and that are also present in these areas [8,22]. The same was seen in South America, where countries such as Brazil, Uruguay, and Argentina, which have the highest HDI, also presented the highest incidence rates [23]. This may be related not only to the possibilities of access to health services but also to risk factors related to the disease, which may contribute to the development 
of CRC, such as age over 50 years; the presence of a family history of bowel cancer; the presence of inflammatory bowel disease or hereditary diseases; obesity; type 2 diabetes mellitus and a past history of malignancy $[1,24]$. Importantly, around $25 \%$ of cases are due to a hereditary factor [25].

According to the data obtained in this study, a reduction in mortality rates in females in the 20-29 age group and an increase in 40-49 years were observed. In males, there was an increase in mortality between 40-49, 50-59 and 60-69 years, with the greatest increase in the latter age group. Similar results were presented in another study carried out in Santa Catarina in 2010, with a tendency to increase mortality due to CRC in both genders and more advanced age groups, despite the difficulty in analyzing mortality in younger age groups due to the occurrence of coefficients with zero values in these ranges [18]. The same occurred in the present study. Differently, studies carried out in developed countries show a decrease in mortality in the elderly population due to CRC and an increase in younger individuals, under 50 years of age $[21,26]$.

Both the increase in hospital morbidity and mortality due to CRC observed in the state of Santa Catarina demonstrate the need to implement early detection programs for the disease, as recommended by National Cancer Institute for people over 50 years old and that do not have other factors risk, through the fecal occult blood test. If the result is positive, colonoscopy or rectumsigmoidoscopy is indicated [1]. Important to note, only $27 \%$ of this population performs this screening in Brazil [27], reflecting the little investment in public policies in this area [28]. If this screening is performed early and on a large scale, the incidence, mortality and economic burden associated with CRC may decrease, as shown by other studies [13,28-30].

It is necessary to include as limitations of this study the obtaining data from MIS and HIS, which may not be completely reliable with reality, since there may be underreporting of hospitalizations and deaths due to CRC, leading to the acquisition of data and underestimated trends.

\section{Conclusion}

Considering the analysis of data on mortality and hospitalization due to CRC in Santa Catarina over a period of 18 years, it could be concluded that there was a significant trend of increase in both indicators: gender and gender-related age group. The male gender shows the largest increases in hospitalization and mortality rates in the period. The trends of increase in hospitalization occur from the age of 30 in both genders. The mortality trend is increased in the age group between 40-49 years in women and 40-69 years in men.

This tendency to increase hospitalization and mortality evidenced in the present study demonstrates the need to institute an effective screening program for CRC in the population and greater access to health services. In the future, this may lead to an inversion in the growing trend observed in the variables, leading to a reduction in these rates, as observed in countries with a high HDI.

\section{Conflict of Interest}

There are no conflicts of interest for the authors listed above.

\section{Bibliography}

1. Instituto Nacional de Câncer. Tipos de câncer: "Câncer de Intestino" (2019).

2. International Agency for Cancer Research. GLOBOCAN 2018: section of cancer information (2019).

3. Instituto Nacional de Câncer. Estimativa 2018: incidência de câncer no Brasil (2019).

4. Arnold M., et al. "Global patterns and trends in colorectal cancer incidence and mortality". Gut 66.4 (2017): 683-691.

5. Instituto Nacional de Câncer. Estimativa 2008: incidência de câncer no Brasil (2019).

6. Moghadamyeghaneh Z., et al. "Trends in colorectal cancer admissions and stage at presentation: impact of screening". Surgical Endoscopy 30.8 (2016): 3604-3610.

7. Dutra VGP., et al. "Evolution of mortality for colorectal cancer in Brazil and regions, by sex, 1996-2015". Arquivos de Gastroenterologia 55.1 (2018): 61-65.

8. Menezes CCS., et al. "Câncer colorretal na população brasileira: taxa de mortalidade no período de 2005-2015". Revista Brasileira em Promoção da Saúde 29.2 (2016): 172-179.

9. Oliveira MM., et al. "Disparidades na mortalidade de câncer colorretal nos estados brasileiros". The Revista Brasileira de Epidemiologia 21 (2018): 1-14. 
10. Instituto Brasileiro de Geografia e Estatística. Atlas do censo demográfico 2018. Rio de Janeiro; IBGE (2019).

11. International Agency for Cancer Research. "GLOBOCAN 2008". Section of cancer information (2020).

12. Lu XQ., et al. "International incidence trends in early- and lateonset colorectal cancer: a population-based study". The International Journal of Colorectal Disease 35.6 (2020): 1077-1086.

13. Darbà $\mathrm{J}$ and Marsà "A Results after 10 years of colorectal cancer screenings in Spain: Hospital incidence and in-hospital mortality (2011-2016)". PLOS ONE 15.2 (2020): e0228795.

14. Sonnenberg A and Byrd-Clark DD. "US. Hospitalizations for Colorectal Cancer 1970-2010". Digestive Diseases and Sciences 59.2 (2014): 282-286.

15. Yuan GL., et al. "Hospitalization costs of treating colorectal cancer in China: A retrospective analysis". Medicine (Baltimore) 98.33 (2019): e16718.

16. Silva AA., et al. "Morbimortalidade hospitalar por câncer colorretal no Brasil, no período de 2008 a 2016". Revista Eletrônica Acervo Científico 5 (2019): e939.

17. Ionescu EM., et al. "Colorectal Cancer Trends of 2018 in Romania-an Important Geographical Variation Between Northern and Southern Lands and High Mortality Versus European Averages". Journal of gastrointestinal cancer 52.1 (2020): 222228.

18. Vasques ALR and Peres A. "Tendência temporal da mortalidade por câncer de cólon e reto em Santa Catarina no período entre 1980 a 2006". Epidemiologia e Serviços de Saúde 19.2 (2010): 91-100.

19. Santos AP., et al. "Tendência da Mortalidade por Câncer Colorretal no Estado do Paraná e no Município de Foz do Iguaçu, 1980 a 2013". Revista Brasileira de Cancerologia 63.2 (2017): 87-93.

20. La Vecchia C., et al. "Cancer mortality in Europe, 2000-2004, and an overview of trends since 1975". Annals of Oncology 21.6 (2010): 1323-1360.

21. Siegel RL., et al. "Colorectal cancer statistics". CA: A Cancer Journal for Clinicians 70.3 (2020): 145-164.

22. Bray F., et al. "Global cancer statistics 2018: GLOBOCAN estimates of incidence and mortality worldwide for 36 cancers in 185 countries". CA: A Cancer Journal for Clinicians 68.6 (2018): 394-424.
23. Sierra MS and Forman D. "Burden of colorectal cancer in Central and South America”. Cancer Epidemiology 44.1 (2016): S74-S81.

24. American Cancer Society. Risk factors. Cancer. Organization (2019).

25. Connell LC., et al. "The Rising Incidence of Younger Patients with Colorectal Cancer: Questions About Screening, Biology, and Treatment". Current Treatment Options in Oncology 18.23 (2017): 1-20.

26. Ellis L., et al. "Colorectal Cancer Incidence Trends by Age, Stage, and Racial/Ethnic Group in California, 1990-2014". Cancer Epidemiology, Biomarkers and Prevention 27.9 (2018): 1011-1018.

27. The Angiogenesis Foundation. Improving outcomes in the treatment and management of metastatic colorectal cancer in Latin America (2019).

28. Mendonça R., et al. "Tendência de mortalidade por câncer colorretal em cinco capitais brasileiras de 1980 a 2009". Cadernos Saúde Coletiva 20.3 (2012): 329-335.

29. Schreuders EH., et al. "Colorectal cancer screening: a global overview of existing programmes". Gut 64.10 (2015): 16371649.

30. Smith RA., et al. "Cancer screening in the United States, 2011: A review of current American Cancer Society guidelines and issues in cancer screening". CA: A Cancer Journal for Clinicians 61.1 (2011): 8-30.

\section{Volume 4 Issue 12 December 2021}

(C) All rights are reserved by Esthefânia de Souza Maciel., et al. 